Case Report

\title{
Early Identification of Traumatic Durotomy Associated with Atlantooccipital Dislocation May Prevent Retropharyngeal Pseudomeningocele Development
}

\author{
Robert S. Qiu, Mina G. Safain, Max Shutran, Alejandra M. Hernandez, \\ Steven W. Hwang, and Ron I. Riesenburger \\ Department of Neurosurgery, Tufts Medical Center and Tufts University School of Medicine, Boston, MA 02111, USA \\ Correspondence should be addressed to Ron I. Riesenburger; rriesenburger@tuftsmedicalcenter.org
}

Received 24 February 2015; Accepted 19 April 2015

Academic Editor: Yoshiharu Kawaguchi

Copyright ( 2015 Robert S. Qiu et al. This is an open access article distributed under the Creative Commons Attribution License, which permits unrestricted use, distribution, and reproduction in any medium, provided the original work is properly cited.

\begin{abstract}
Atlantooccipital dislocation can be complicated by a traumatic durotomy that may lead to the rare development of a retropharyngeal pseudomeningocele. To our knowledge this has been reported only five times previously. We present the case of a 60-year-old man involved in a motor vehicle accident who suffered an atlantooccipital dislocation and C5-C6 three-column injury. A unique MRI image of a defect in the ventral dura posterior to $\mathrm{C} 2$ was appreciated. He underwent occiput to T2 internal fixation and arthrodesis. During surgery, CSF egress was seen caudal to the right C2 nerve root. A DuraMatrix onlay patch reinforced with DuraSeal was placed to stop the CSF leak. A lumbar subarachnoid drain was also placed. The patient made a satisfactory recovery with residual mild weakness of his right upper extremity. In this report, we demonstrate that careful MRI review can reveal a ventral durotomy in a traumatic atlantooccipital dislocation and, if discovered, effective treatment including a lumbar subarachnoid drain for CSF diversion may prevent progression to a retropharyngeal pseudomeningocele. The literature on this rare presentation and associated durotomy is provided.
\end{abstract}

\section{Introduction}

Traumatic atlantooccipital dislocation (AOD) is an uncommon injury that frequently results in death. Improvements in care and early diagnosis of the condition have led to an increased number of patients surviving, but this disease entity is still associated with significant morbidity and complications [1-3]. An unusual complication associated with AOD is the development of a retropharyngeal pseudomeningocele in a delayed fashion with five current reports in the literature [2-6]. Its development is the result of cerebrospinal fluid extravasating and collecting in the retropharyngeal space in the setting of a traumatic durotomy $[2,4,6]$. Previous reports have suggested that a delay in the diagnosis of a retropharyngeal pseudomeningocele can lead to worse outcomes and can be associated with development of hydrocephalus and syringomyelia [2-6].

Most reported cases in the literature have intraoperatively identified the presence of a durotomy after the development of a symptomatic retropharyngeal pseudomeningocele. In the current report, we present a case of AOD where a traumatic durotomy was seen on magnetic resonance imaging (MRI) upon initial patient presentation. This unique image of the ventral dural tear was captured and is presented here (Figure 1). The patient had posterior surgery to stabilize the AOD, and cerebrospinal fluid (CSF) extravasation was treated with a dural patch and 5 days of cerebrospinal fluid diversion via lumbar subarachnoid drainage. The patient did not develop a symptomatic retropharyngeal pseudomeningocele and has done well neurologically.

\section{Case Report}

A 60-year-old unrestrained intoxicated driver presented to our emergency department after a motor vehicle accident. Initial examination revealed proximal upper extremity weakness and severe hoarseness, concerning for vagus nerve injury. He was intubated for airway protection and had subsequent computed tomography (CT) and MRI of his cervical spine. MRI demonstrated evidence of AOD (Figure 1). Short 


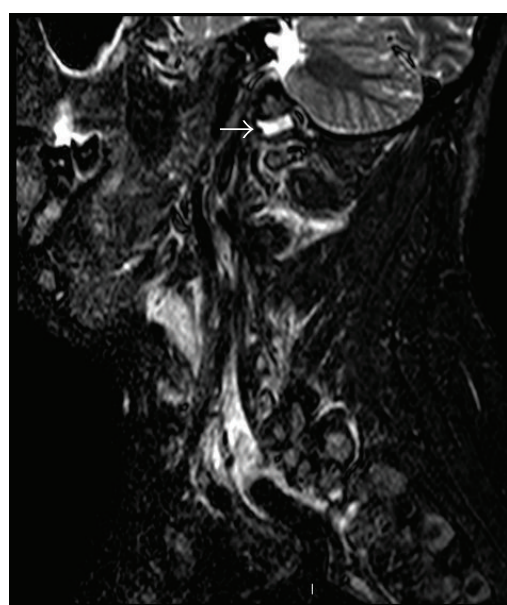

(a)

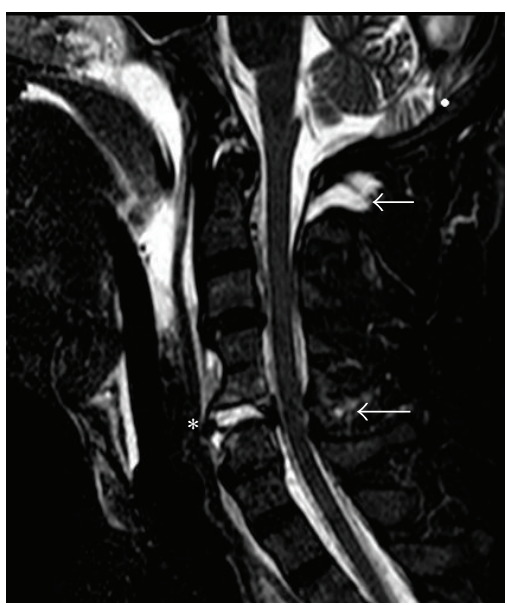

(c)

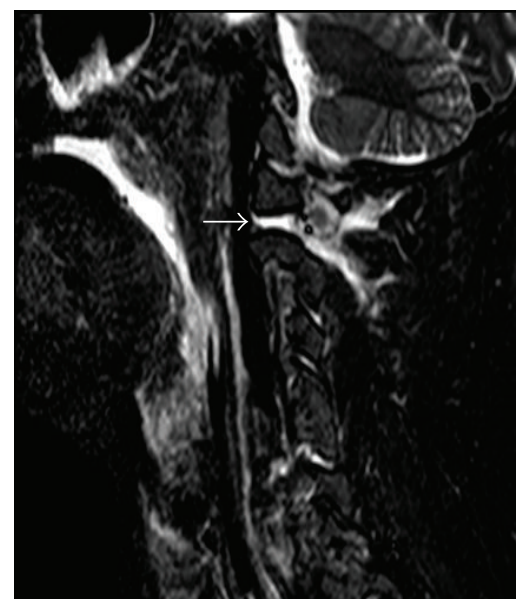

(b)

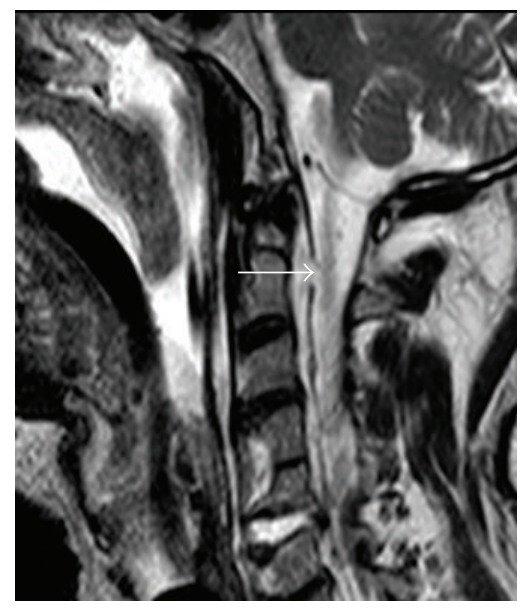

(d)

FIGURE 1: Multiple preoperative sagittal magnetic resonance images (MRI). (a) Left parasagittal short tau inversion recovery (STIR) image demonstrating abnormal fluid in the left atlantooccipital joint (arrow). (b) Left parasagittal STIR image demonstrating abnormal fluid in the left C1-C2 joint (arrow). (c) Midline sagittal STIR image demonstrating disk disruption at the C5-C6 level (*) and abnormal signal demonstrating posterior ligamentous injury at the occiput-C1 level (rostral arrow) and at the C5-C6 level (caudal arrow). (d) Sagittal T2weighted MRI demonstrating ventral dural defect at the level of C2 (arrow).

tau inversion recovery (STIR) images demonstrated a large amount of fluid in both atlantooccipital joints (Figure 1(a)) as well as both C1-C2 joint complexes (Figure 1(b)). A threecolumn C5-C6 injury was also apparent and involved the disk space and posterior ligamentous complex (Figure 1(c)). Importantly, the MRI demonstrated a large defect in the ventral dura at the C2 level (Figure 1(d)).

The patient was thought to have two unstable cervical spine injuries and was taken to the operating room for immediate surgical stabilization. He underwent a posterior internal fixation and arthrodesis from occiput to T2 (Figure 2). During surgery, a CSF leak was encountered emanating caudal to the right $\mathrm{C} 2$ nerve root. The origin of the CSF leak was unable to be visualized due to its ventral location. To prevent posterior CSF egress, a DuraMatrix patch (Stryker, MI, USA) supplemented with DuraSeal (Covidien, MA, USA) was placed caudal to the C2 nerve root. While we felt this technique may prevent CSF egress posteriorly, thus preventing a potential postoperative cerebrospinal-cutaneous fistula, it did not address the defect in the ventral dura. For this reason, a lumbar subarachnoid drain was placed for CSF diversion with the goal that the ventral durotomy would scar. CSF drainage was continued at $10 \mathrm{~mL}$ per hour for 5 days. The patient was extubated 4 days after injury with continued hoarseness after extubation. A percutaneous gastrostomy tube was placed for feeding and removed at 2 months after his hoarseness resolved. One-year follow-up demonstrates some slight dysphagia, full strength in his left upper extremity, and mild weakness (4/5) in his right upper extremity.

\section{Discussion}

Traumatic AOD can involve a ventral durotomy that has been reported to develop into a retropharyngeal pseudomeningocele. However, the exact incidence of retropharyngeal pseudomeningocele development in AOD is unknown because 
TABLE 1: Cases of retropharyngeal pseudomeningocele following AOD.

\begin{tabular}{|c|c|c|c|c|c|c|c|c|}
\hline Author & Year & Age & $\begin{array}{c}\text { AOD } \\
\text { management }\end{array}$ & Symptom & $\begin{array}{c}\text { Diagnosis } \\
\text { of RP }\end{array}$ & Hydrocephalus & $\begin{array}{c}\text { Treatment } \\
\text { of RP }\end{array}$ & Outcome \\
\hline Williams et al. [3] & 1995 & 3.5 & Arthrodesis & $\begin{array}{c}\text { Respiratory } \\
\text { and dysphagia }\end{array}$ & 4 weeks & Yes & VP shunt & $\begin{array}{c}\text { Resolution } \\
\text { of RP }\end{array}$ \\
\hline \multirow[t]{2}{*}{ Naso et al. [5] } & 1997 & 26 & Halo & $\begin{array}{c}\text { Respiratory } \\
\text { and dysphagia }\end{array}$ & 3.5 months & Yes & VP shunt & $\begin{array}{l}\text { Resolution } \\
\text { of RP }\end{array}$ \\
\hline & 1997 & 11 & Unknown & Respiratory & 5 weeks & Yes & None & Died \\
\hline Reed et al. [6] & 2005 & 9 & Arthrodesis & Incidental & 4 weeks & Yes & None & Died \\
\hline Cognetti et al. [2] & 2006 & 19 & Arthrodesis & Dysphagia & 6 weeks & No & LP shunt & $\begin{array}{l}\text { Resolution } \\
\text { of RP }\end{array}$ \\
\hline $\begin{array}{l}\text { Gutiérrez-González } \\
\text { et al. [4] }\end{array}$ & 2008 & 29 & Hard collar & Respiratory & 3 weeks & No & None & Died \\
\hline $\begin{array}{l}\text { Qiu et al. } \\
\text { (current report) }\end{array}$ & 2013 & 60 & Arthrodesis & $\begin{array}{l}\text { Respiratory, } \\
\text { weakness }\end{array}$ & No RP & No & None & No RP \\
\hline
\end{tabular}

AOD: atlantooccipital dislocation, VP: ventriculoperitoneal, LP: lumboperitoneal, and RP: retropharyngeal pseudomeningocele.

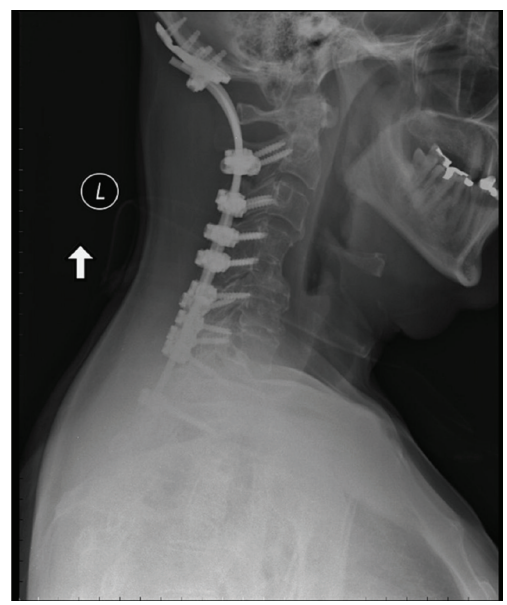

FIGURE 2: Postoperative lateral X-ray demonstrating posterior instrumentation from the occiput to $\mathrm{T} 2$.

there are only a few reports in the literature (Table 1) [2-6]. In our analysis of those case series with 3 or more patients with AOD, the incidence of traumatic durotomy varied from $6 \%$ to $75 \%[7,8]$ but was not mentioned in the vast majority of case series [9-14]. Thus, it is currently uncertain what percentage of patients with AOD will have a traumatic durotomy and what percentage will subsequently develop retropharyngeal pseudomeningocele if left untreated.

Currently all reported retropharyngeal pseudomeningoceles were not diagnosed until several weeks to several months later, usually following symptoms of dysphagia and/or respiratory distress [2-6]. However, these presenting symptoms are not specific because they can also be attributed to bulbar-medullary and vagal nerve injury sustained during the AOD [1-4]. Cases of retropharyngeal pseudomeningocele have also been associated with hydrocephalus and syringomyelia, both resulting in worse outcomes $[3,5,6]$. In patients with delayed dysphagia, MRI of the brain and cervical spine is indicated to look for a retropharyngeal pseudomeningocele and concurrently rule out syringomyelia and hydrocephalus. In our case, preoperative MRI clearly identified a traumatic durotomy which was corroborated by intraoperative findings and modified our management (Figure 1(d)).

Initial conservative treatment of a retropharyngeal pseudomeningocele with head elevation, bed rest, and acetazolamide was not successful as reported by Cognetti et al. [2] and these authors advocated surgical placement of cerebrospinal diverting shunts. Resolution of retropharyngeal pseudomeningoceles has been accomplished with ventriculoperitoneal shunting in patients with concomitant hydrocephalus [3,5] and lumboperitoneal shunting in patients with pseudomeningocele without associated hydrocephalus $[2,3]$.

In this current report, a ventral traumatic durotomy was seen on MRI and CSF egress was confirmed during surgery. Because of the morbidity associated with the development of a retropharyngeal pseudomeningocele, MRI scans that demonstrate AOD should be assessed for a ventral durotomy. Early identification of this abnormality can suggest to the surgeon that additional treatments during surgical stabilization may be necessary in order to prevent formation of a retropharyngeal pseudomeningocele. In this case, treatment of a ventral dural tear was not completely accomplished with a dural substitute patch. While this step helps prevent posterior cerebrospinal fluid egress and decrease the likelihood of developing a posterior CSF-cutaneous fistula, it does not treat the ventral durotomy. We felt that the ventral durotomy should be addressed to decrease the chance of retropharyngeal pseudomeningocele development. However, we also felt that an additional transoral surgical approach for direct primary repair was not indicated because it would carry a high risk of postoperative meningitis. We therefore elected to treat this with the addition of a lumbar subarachnoid drain for aggressive cerebrospinal fluid diversion over five days. We thought that this would likely give the ventral durotomy enough time to seal.

We theorize that, in order for a retropharyngeal pseudomeningocele to form, several atlantooccipital structures must be injured. We suspect this would include a ventral durotomy, a disruption of the PLL/tectorial membrane, and 
ALL/anterior atlantooccipital membrane. It is difficult to clearly identify complete disruptions to the PLL/tectorial membrane and ALL/anterior atlantooccipital membrane on MRI imaging. However, this study shows that careful MRI review can reveal a ventral durotomy following AOD. In this situation, we recommend strong consideration for placement of a lumbar subarachnoid drain as a temporary measure that may prevent retropharyngeal pseudomeningocele development and avoid the need for permanent CSF diversion. We, like other authors, recommend repeat imaging to rule out a retropharyngeal pseudomeningocele should a patient develop a delayed inability to swallow $[5,6]$.

\section{Disclosure}

This paper has not been previously published in whole or in part or submitted elsewhere for review.

\section{Conflict of Interests}

The authors report no conflict of interests concerning the materials or methods used in this study or the findings specified in this paper.

\section{References}

[1] "Diagnosis and management of traumatic atlanto-occipital dislocation injuries," Neurosurgery, vol. 50, no. 3, pp. S105-S113, 2002.

[2] D. M. Cognetti, W. S. Enochs, and T. O. Willcox, "Retropharyngeal pseudomeningocele presenting as dysphagia after atlantooccipital dislocation," Laryngoscope, vol. 116, no. 9, pp. 1697-1699, 2006

[3] M. J. Williams, J. L. Elliott, and J. Nichols, "Atlantooccipital dislocation: a case report," Journal of Clinical Anesthesia, vol. 7, no. 2, pp. 156-159, 1995.

[4] R. Gutiérrez-González, G. R. Boto, Á. Pérez-Zamarrón, and M. Rivero-Garvía, "Retropharyngeal pseudomeningocele formation as a traumatic atlanto-occipital dislocation complication: case report and review," European Spine Journal, vol. 17, supplement 2, pp. S253-S256, 2008.

[5] W. B. Naso, J. Cure, and B. G. Cuddy, "Retropharyngeal pseudomeningocele after atlanto-occipital dislocation: report of two cases," Neurosurgery, vol. 40, no. 6, pp. 1288-1291, 1997.

[6] C. M. Reed, S. E. Campbell, D. P. Beall, J. S. Bui, and R. M. Stefko, "Atlanto-occipital dislocation with traumatic pseudomeningocele formation and post-traumatic syringomyelia," Spine., vol. 30, no. 5, pp. E128-133, 2005.

[7] V. I. Adams, "Neck injuries: I. Occipitoatlantal dislocation-a pathologic study of twelve traffic fatalities," Journal of Forensic Sciences, vol. 37, no. 2, pp. 556-564, 1992.

[8] C. Bellabarba, S. K. Mirza, G. A. West et al., "Diagnosis and treatment of craniocervical dislocation in a series of 17 consecutive survivors during an 8-year period," Journal of Neurosurgery: Spine, vol. 4, no. 6, pp. 429-440, 2006.

[9] B. C. Grabb, T. A. Frye, G. L. Hedlund, Y. N. Vaid, P. A. Grabb, and S. A. Royal, "MRI diagnosis of suspected atlanto-occipital dissociation in childhood," Pediatric Radiology, vol. 29, no. 4, pp. 275-281, 1999.
[10] E. M. Horn, I. Feiz-Erfan, G. P. Lekovic, C. A. Dickman, V. K. H. Sonntag, and N. Theodore, "Survivors of occipitoatlantal dislocation injuries: Imaging and clinical correlates," Journal of Neurosurgery: Spine, vol. 6, no. 2, pp. 113-120, 2007.

[11] M. J. Matava, T. E. Whitesides Jr., and P. C. Davis, “Traumatic atlanto-occipital dislocation with survival: Serial computerized tomography as an aid to diagnosis and reduction: a report of three cases," Spine, vol. 18, no. 13, pp. 1897-1903, 1993.

[12] C. K. Maves, A. Souza, E. C. Prenger, and D. R. Kirks, "Traumatic atlanto-occipital disruption in children," Pediatric Radiology, vol. 21, no. 7, pp. 504-507, 1991.

[13] I. Montane, F. J. Eismont, and B. A. Green, "Traumatic occipitoatlantal dislocation," Spine, vol. 16, no. 2, pp. 112-116, 1991.

[14] D. Pang, W. R. Nemzek, and J. Zovickian, "Atlanto-occipital dislocation-part 2: the clinical use of (occipital) condyle-C1 interval, comparison with other diagnostic methods, and the manifestation, management, and outcome of atlanto-occipital dislocation in children," Neurosurgery, vol. 61, no. 5, pp. 9951015, 2007. 


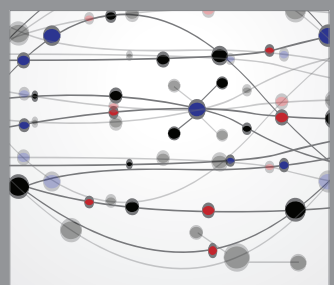

The Scientific World Journal
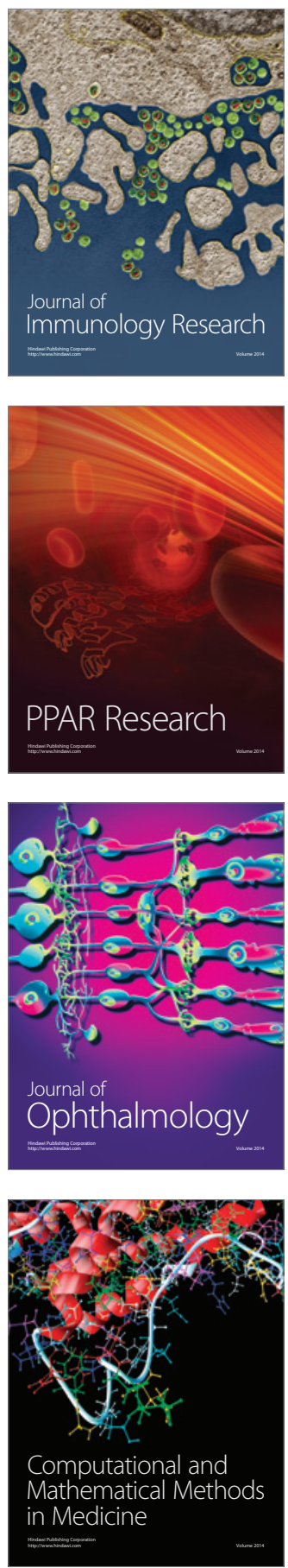

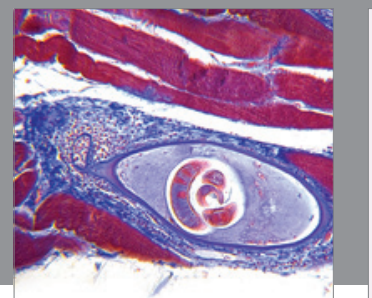

Gastroenterology

Research and Practice
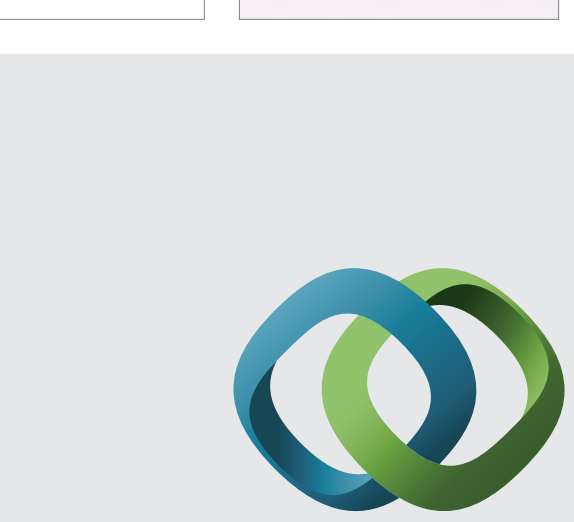

\section{Hindawi}

Submit your manuscripts at

http://www.hindawi.com
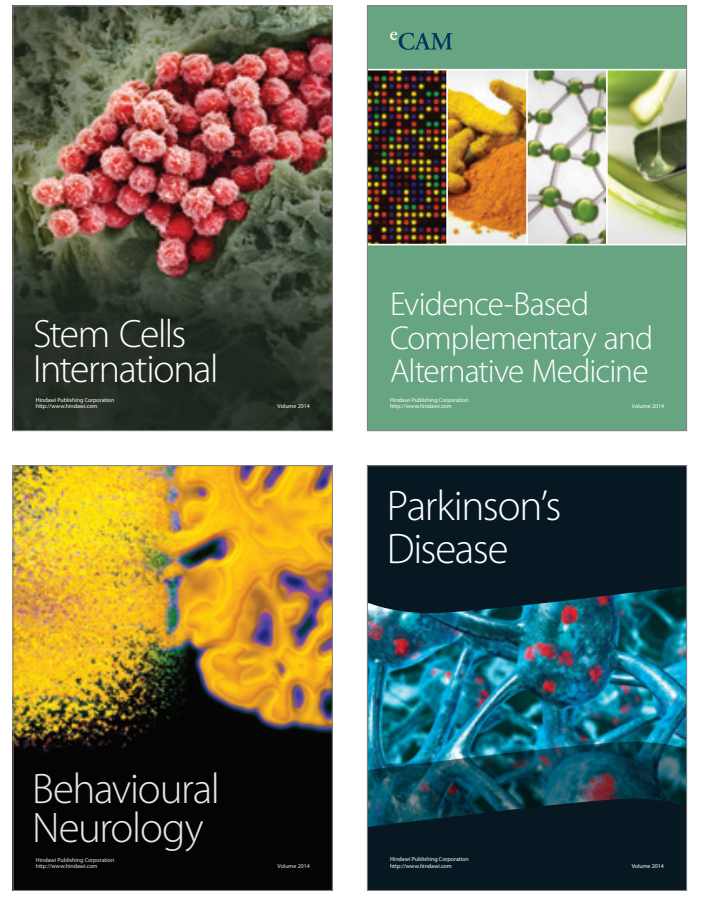
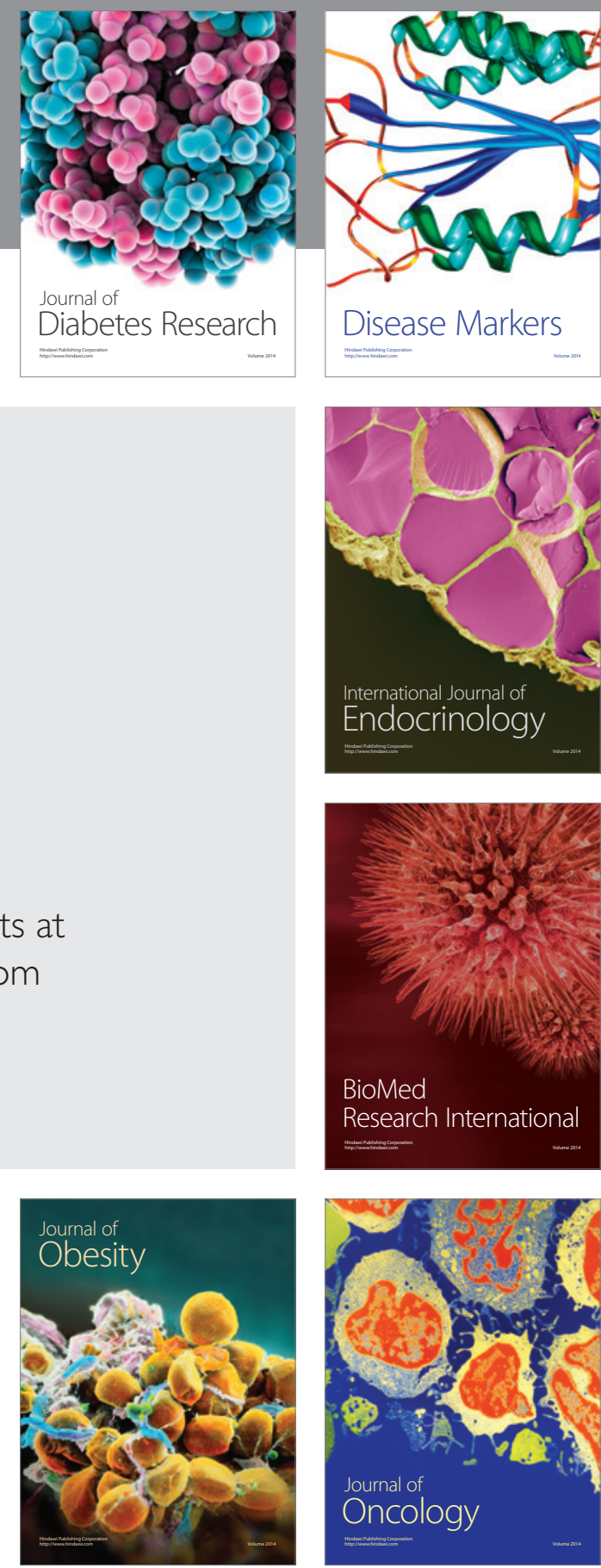

Disease Markers
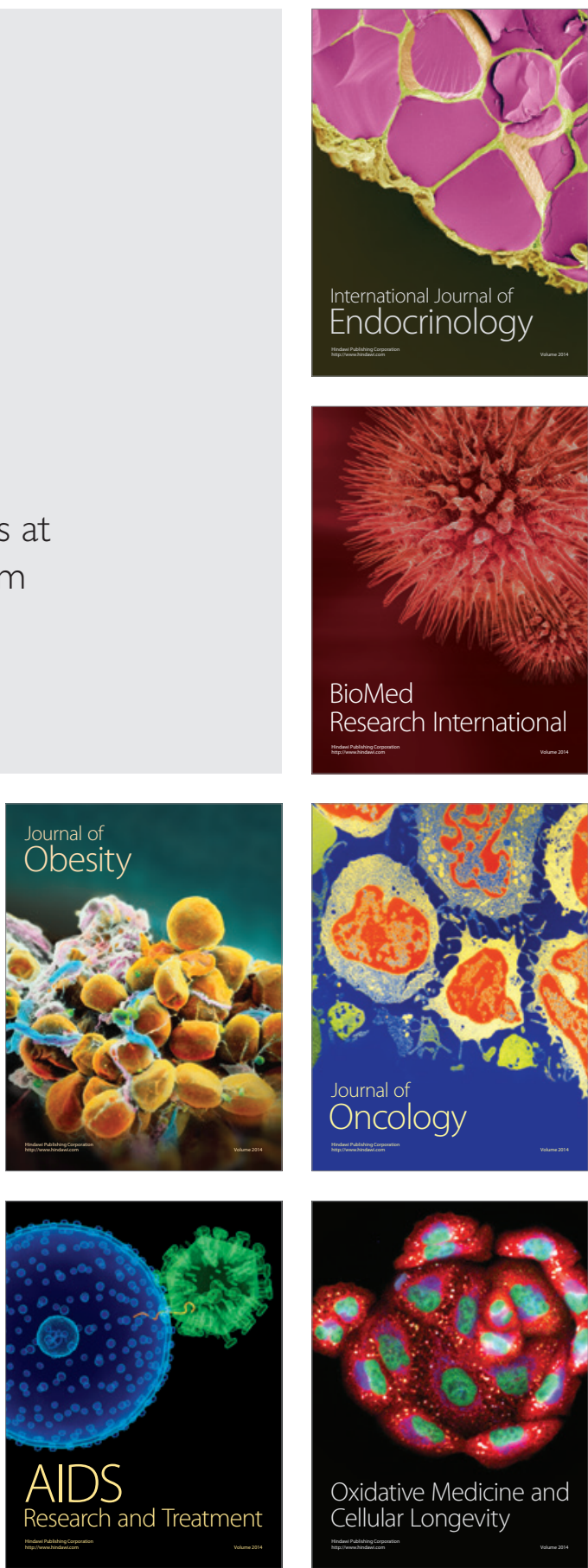